\title{
GLAD!
}

Revue sur le langage, le genre, les sexualités

02 | 2017

Varia

\section{BD (dé)coloniale}

(des)colonialidades nas histórias em quadrinhos

\section{Sujarei Tali}

\section{(2) OpenEdition}

Journals

Édition électronique

URL : http://journals.openedition.org/glad/1879

DOI : $10.4000 /$ glad. 1879

ISSN : 2551-0819

Éditeur

Association GSL

\section{Référence électronique}

Sujarei Tali, «BD (dé)coloniale », GLAD! [En ligne], 02 | 2017, mis en ligne le 01 juin 2017, consulté le 21 janvier 2021. URL : http://journals.openedition.org/glad/1879; DOI : https://doi.org/10.4000/glad. 1879

Ce document a été généré automatiquement le 21 janvier 2021.

\section{(c) (i) (9)}

La revue GLAD! est mise à disposition selon les termes de la Licence Creative Commons Attribution Pas d'Utilisation Commerciale - Pas de Modification 4.0 International. 


\section{BD (dé)coloniale}

(des)colonialidades nas histórias em quadrinhos

Sujarei Tali

Bande dessinée (dé)coloniale

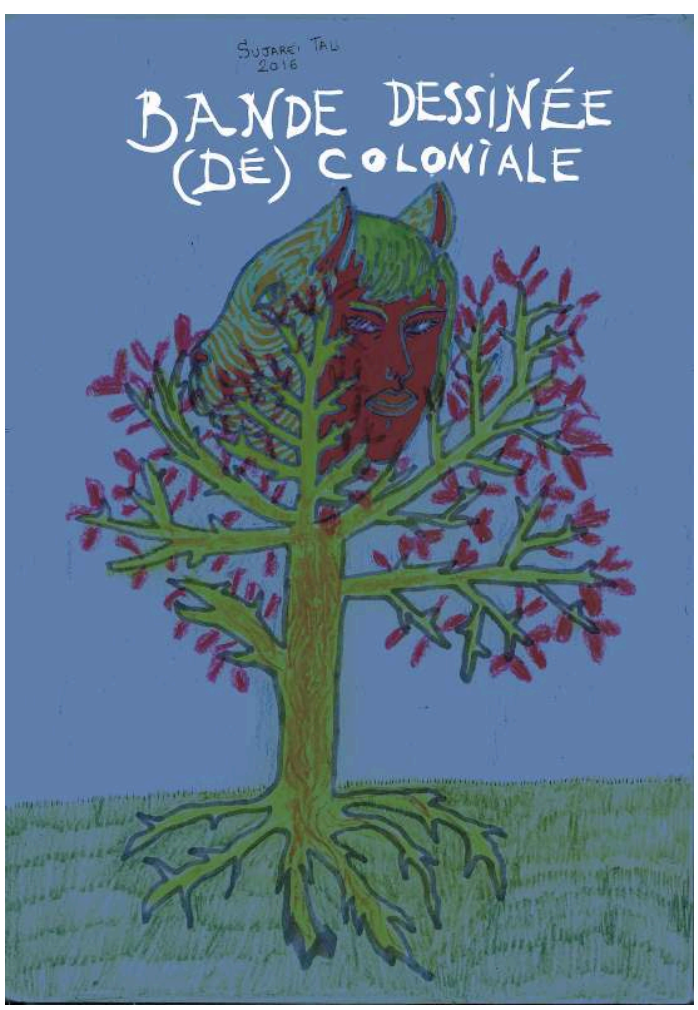




\section{Étendre le questionnement académique à l'imaginaire et la poésie}

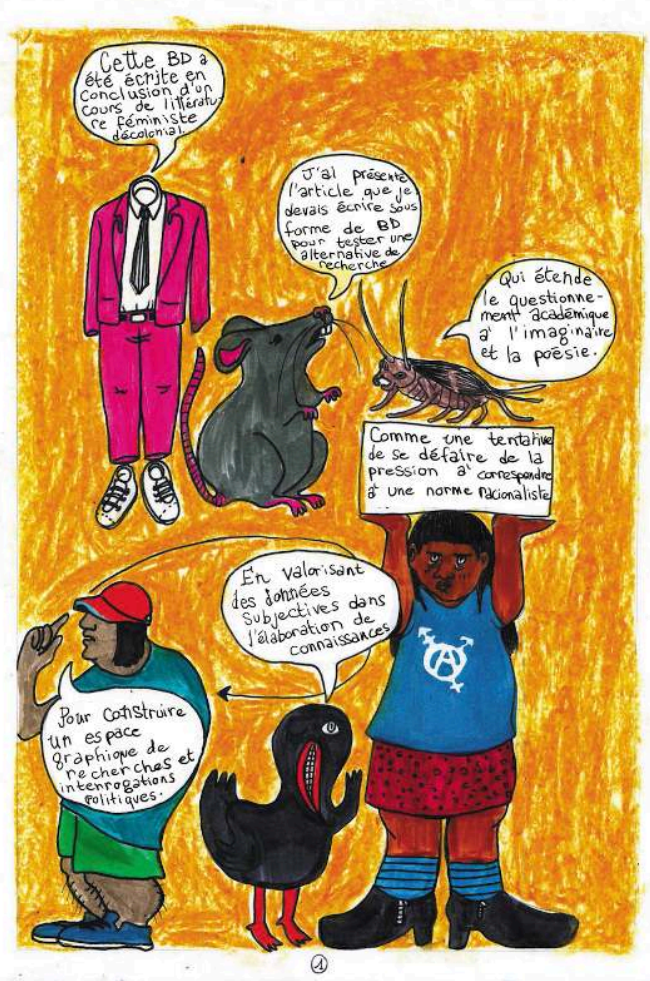

Je n'ai jamais pris de cours de dessin

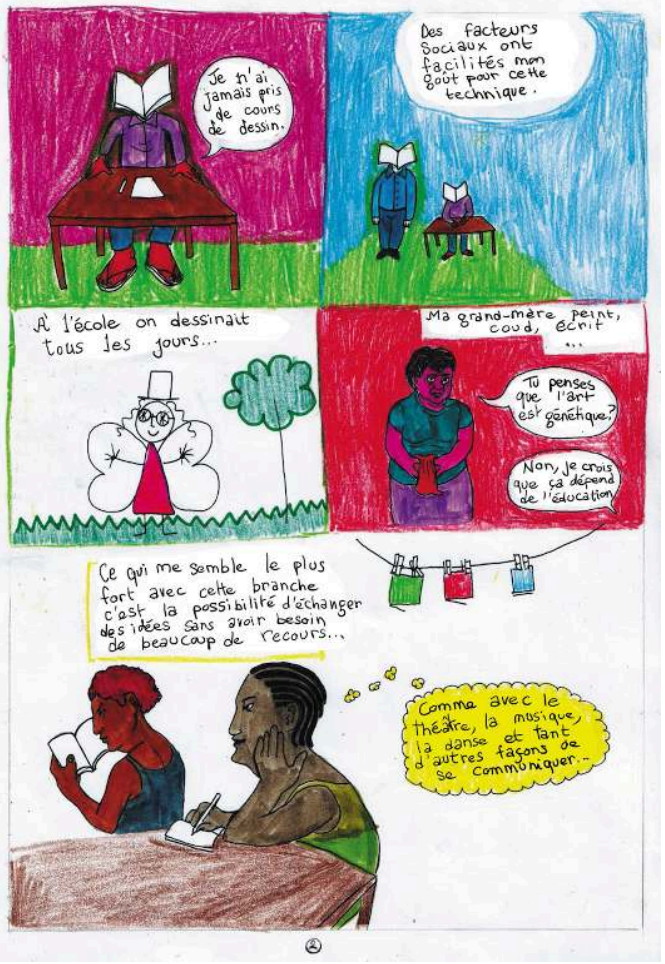


La représentation des gouines en $B D$

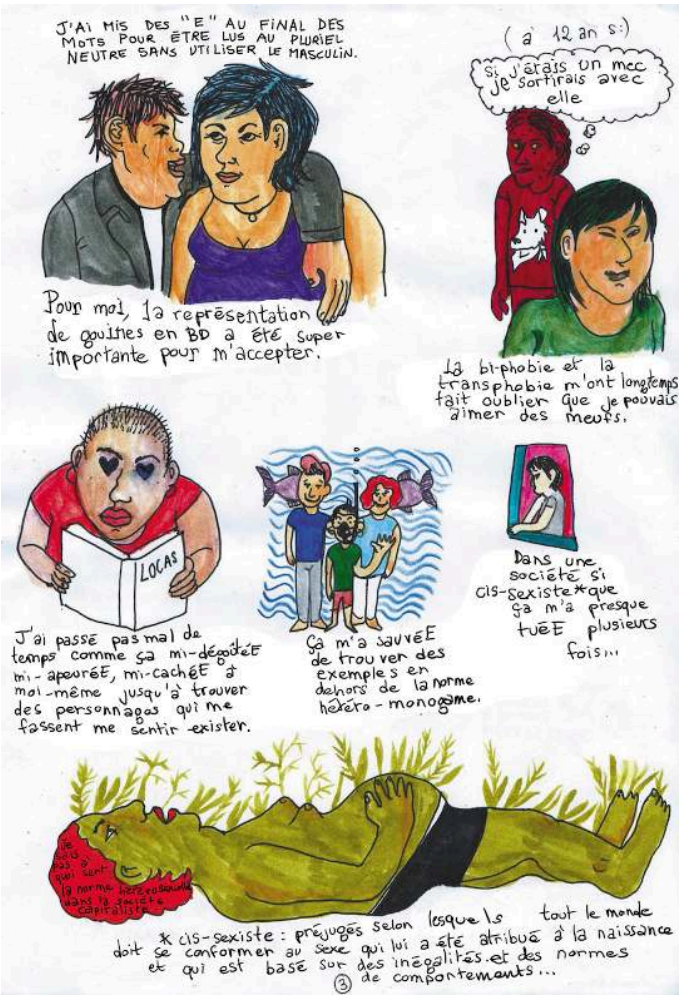

Et pourquoi la bande dessinée peut être un outil décolonial ?

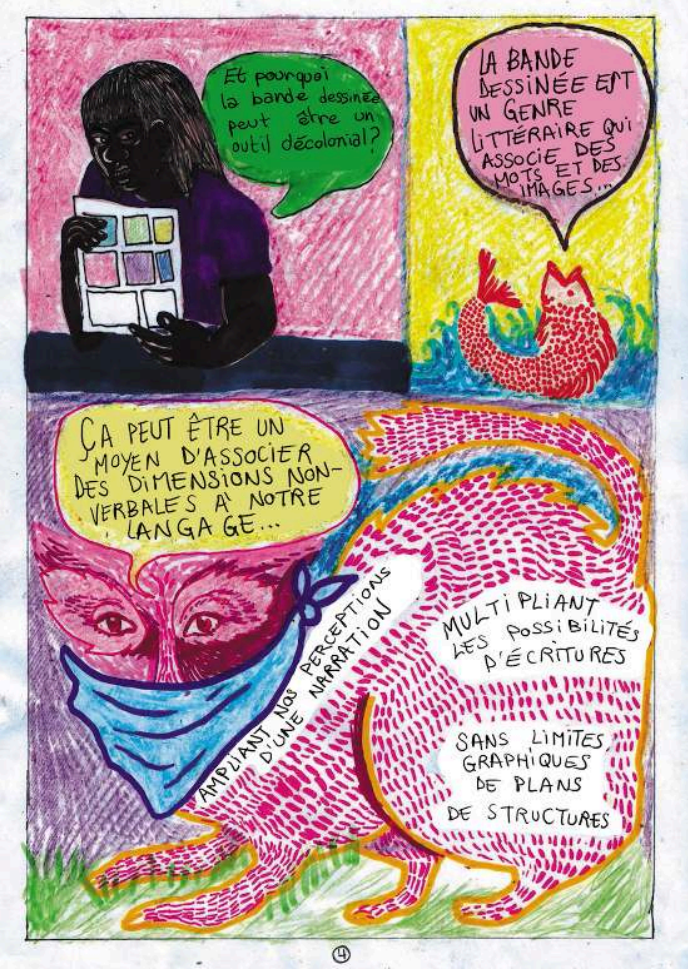


La BD est associée à quelque chose d'enfantin

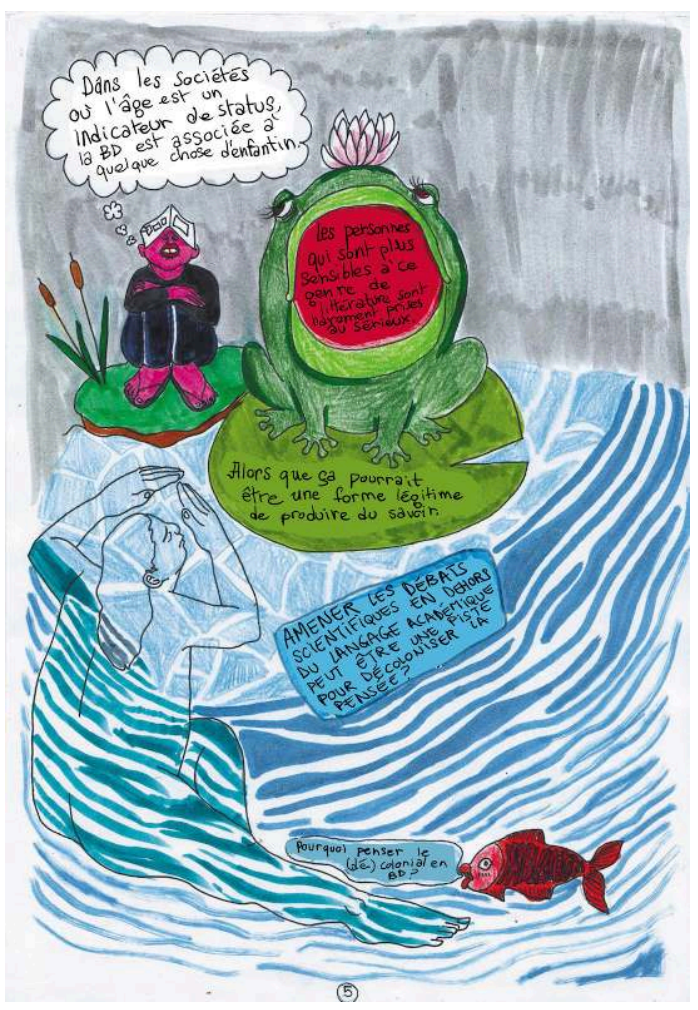

Les formes de colonialisme

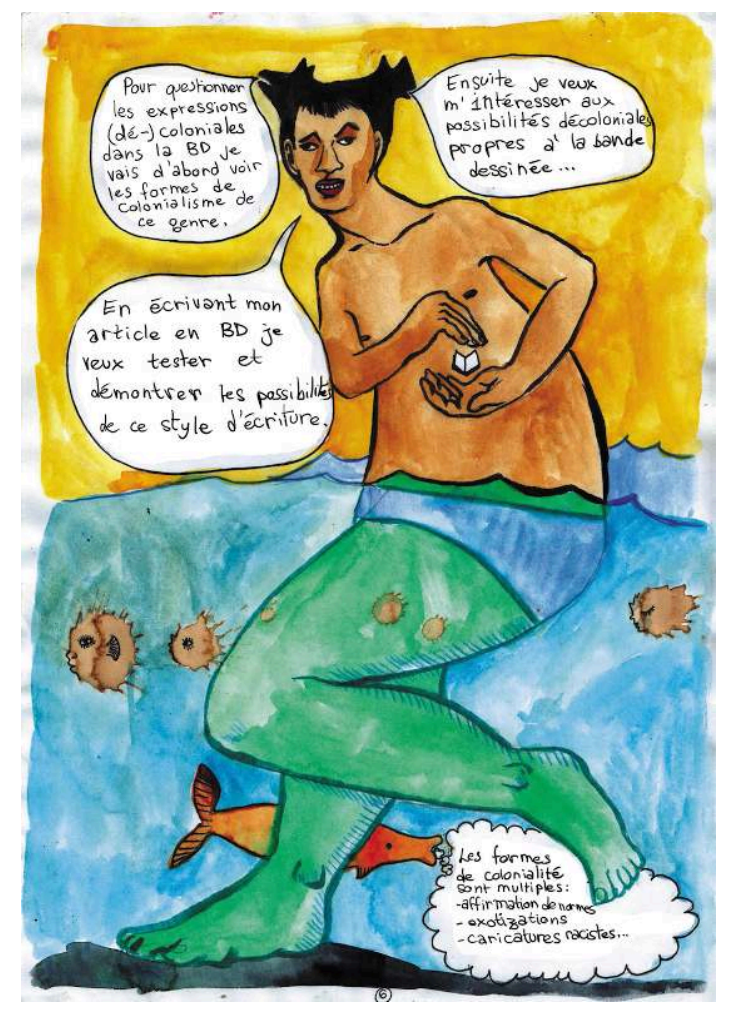


La bande dessinée serait un univers masculin

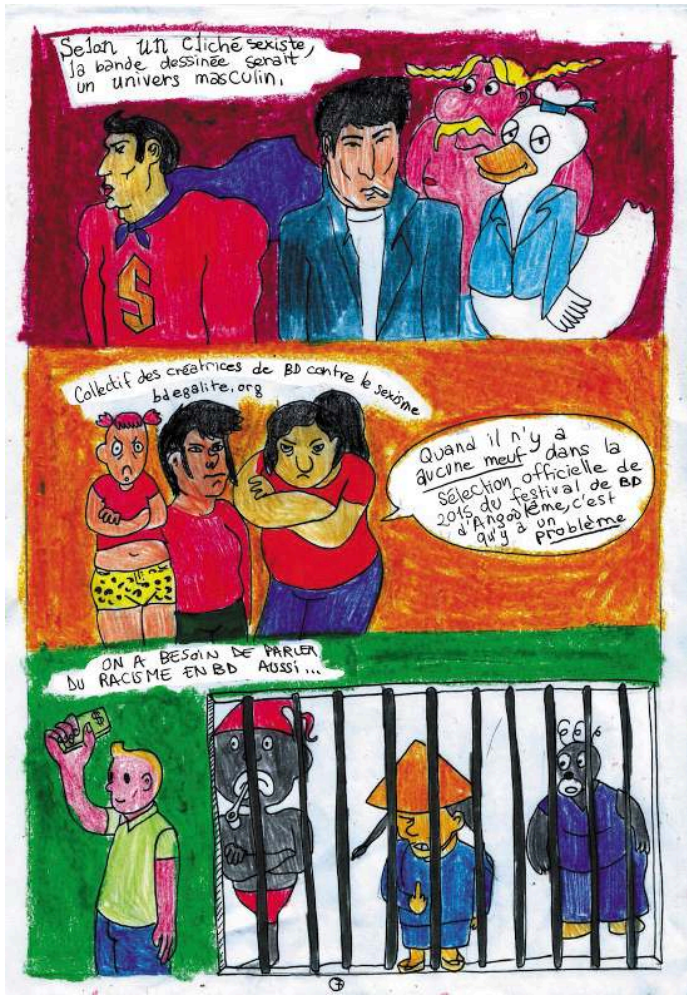

On peut changer l'origine des stéréotypes utilisés

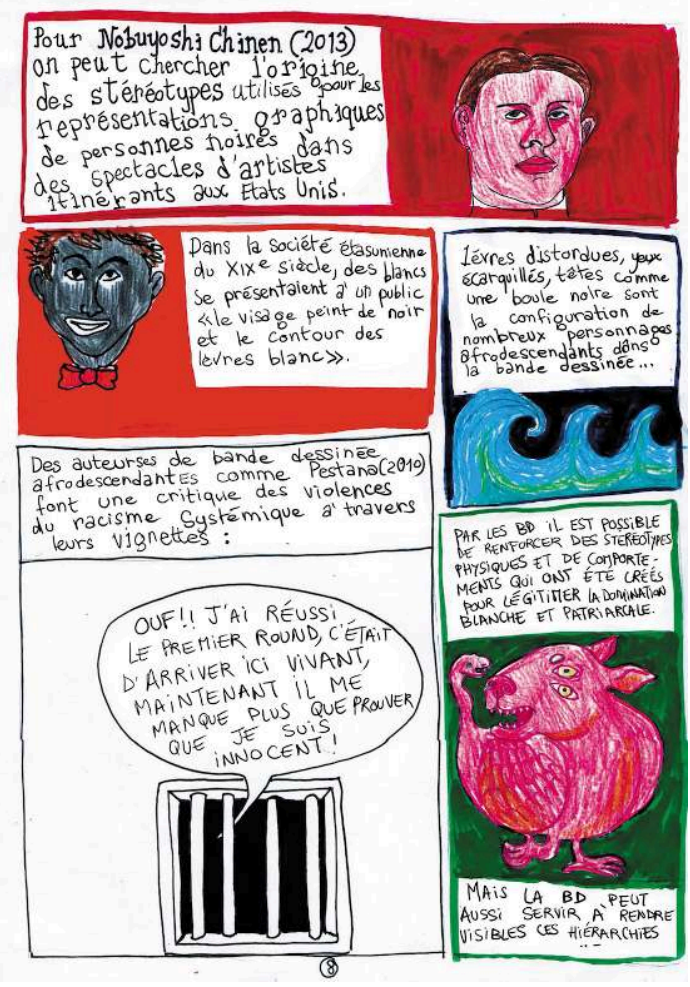


Devant un « Black Face »...

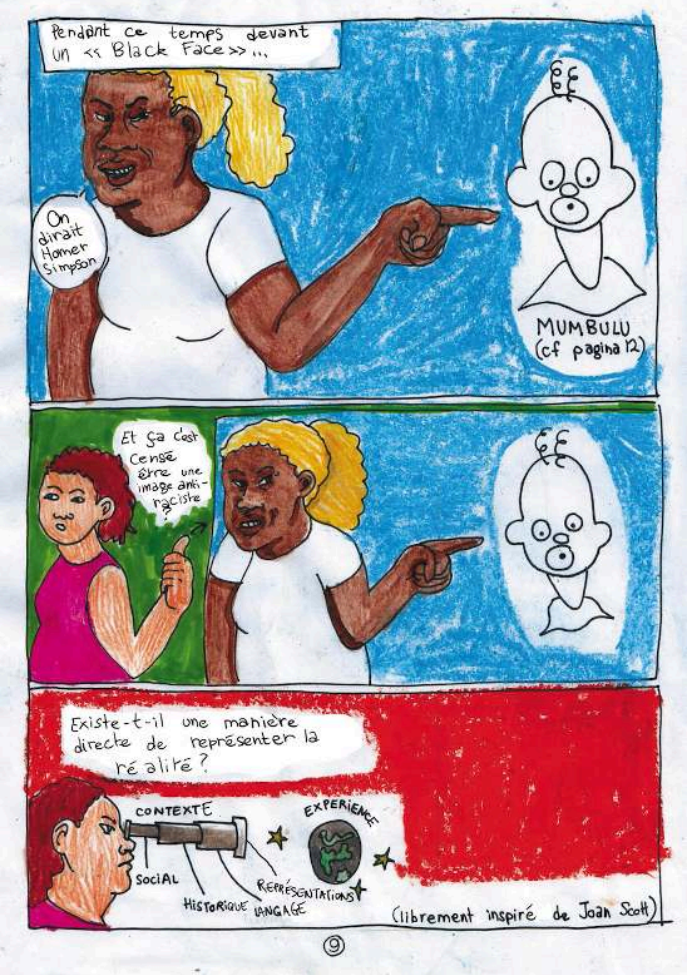

Les BD sont un reflet de la vie sociale

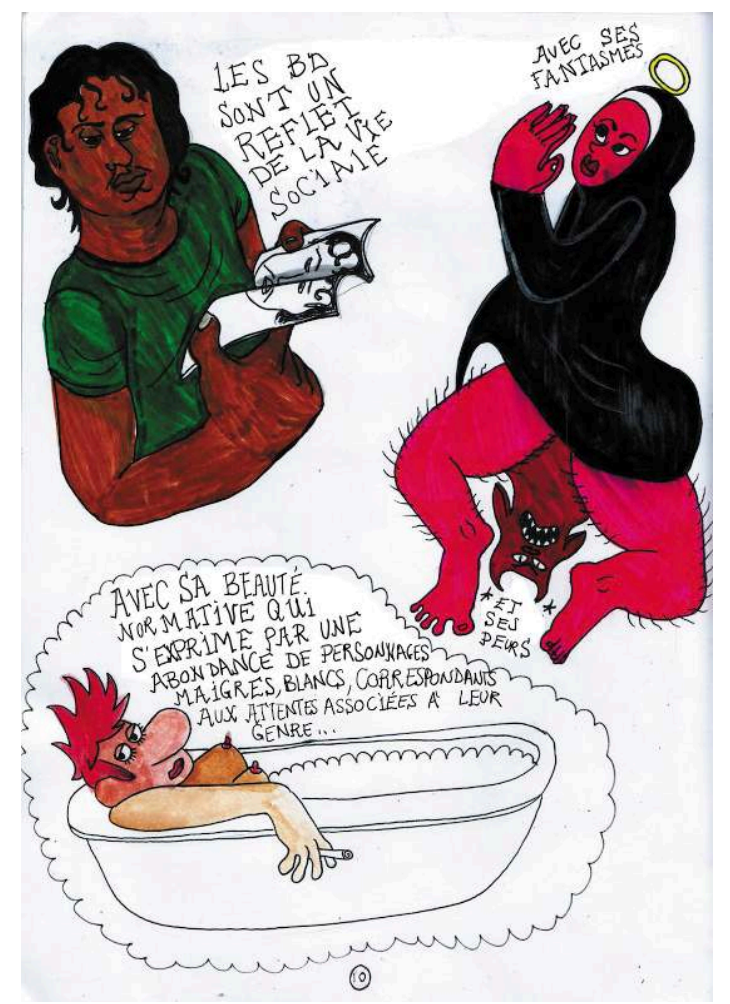


Des maisons d'édition utilisent des stéréotypes sexistes pour vendre...

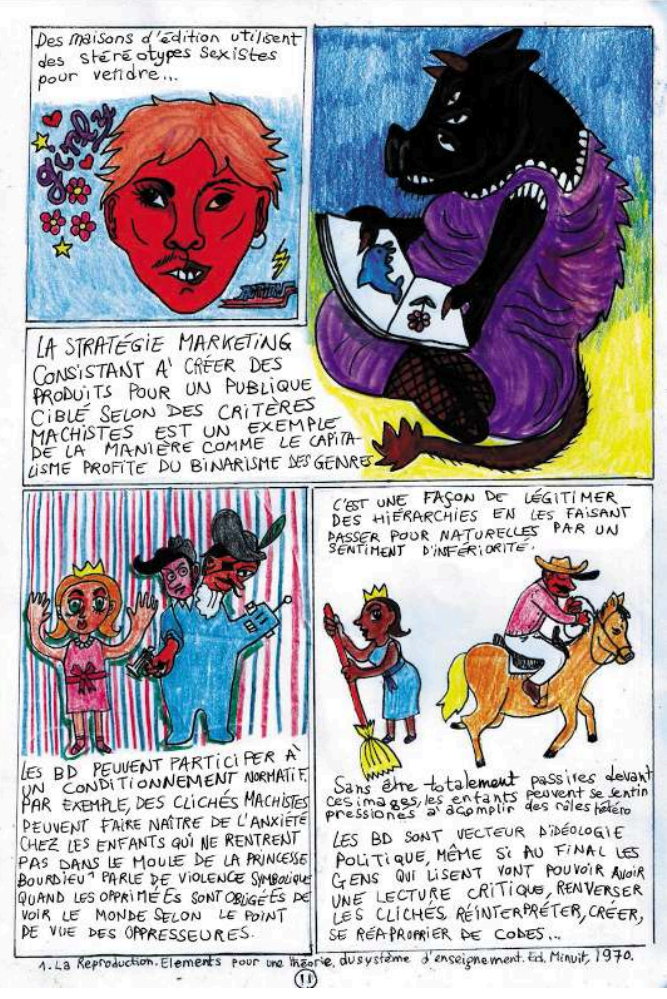

Les BD ont servi/servent le pouvoir colonial

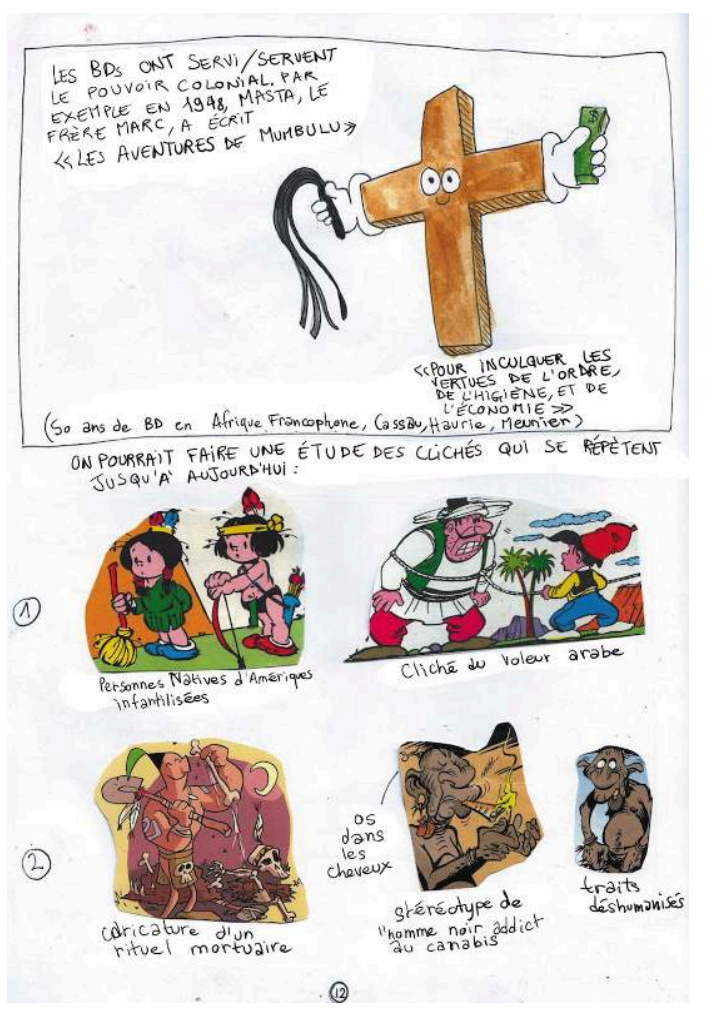


Des exemples tirés de magazines ramassés de façon aléatoire

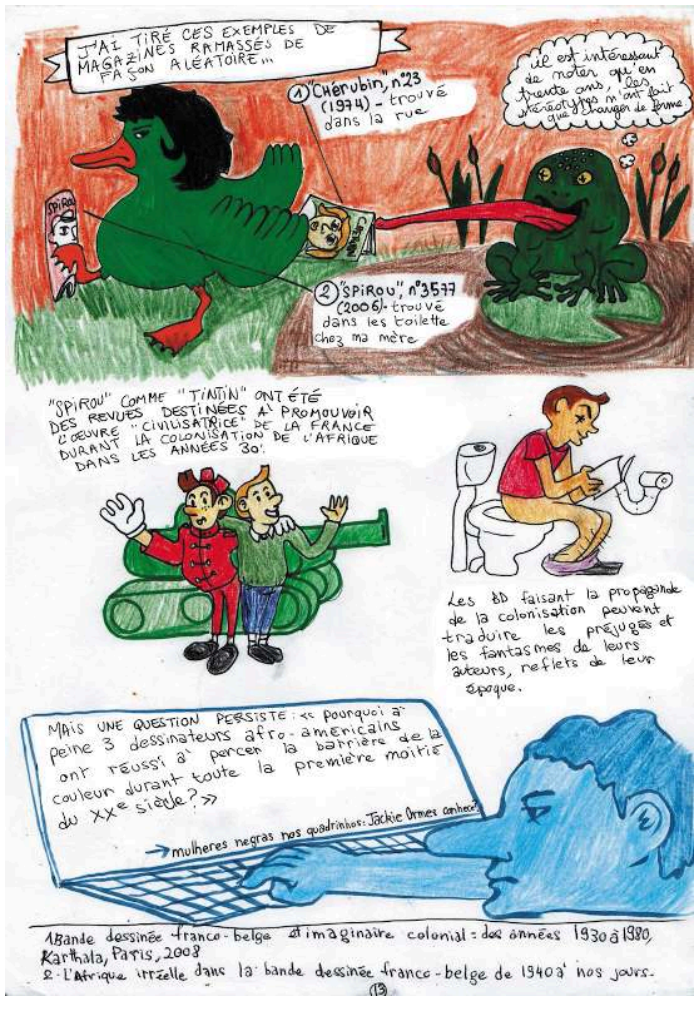

Les formes de colonialités en BD

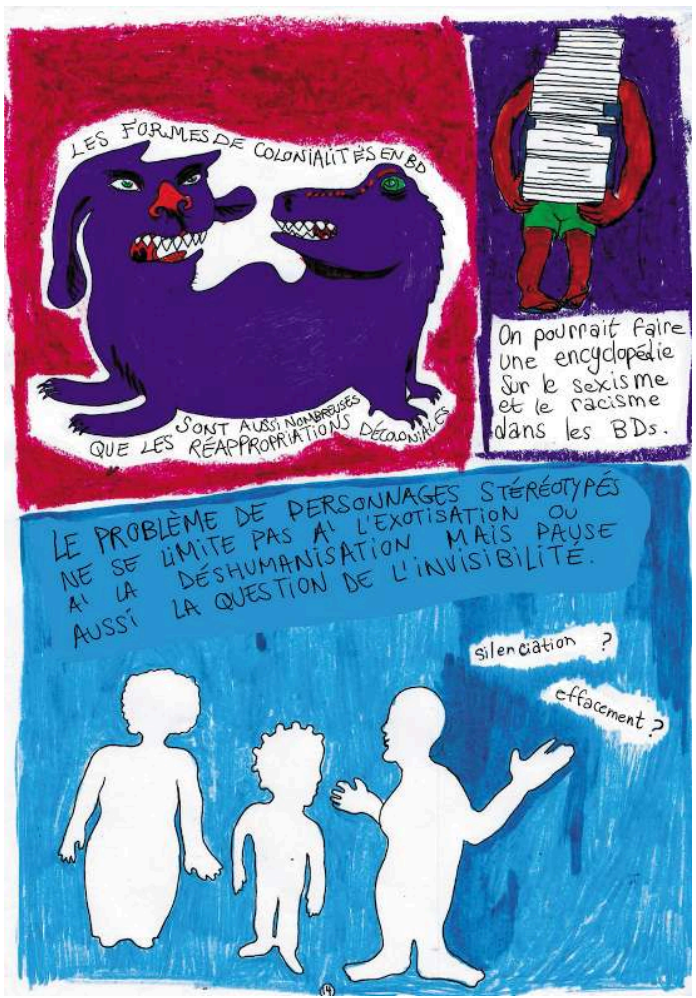




\section{La représentativité est importante}

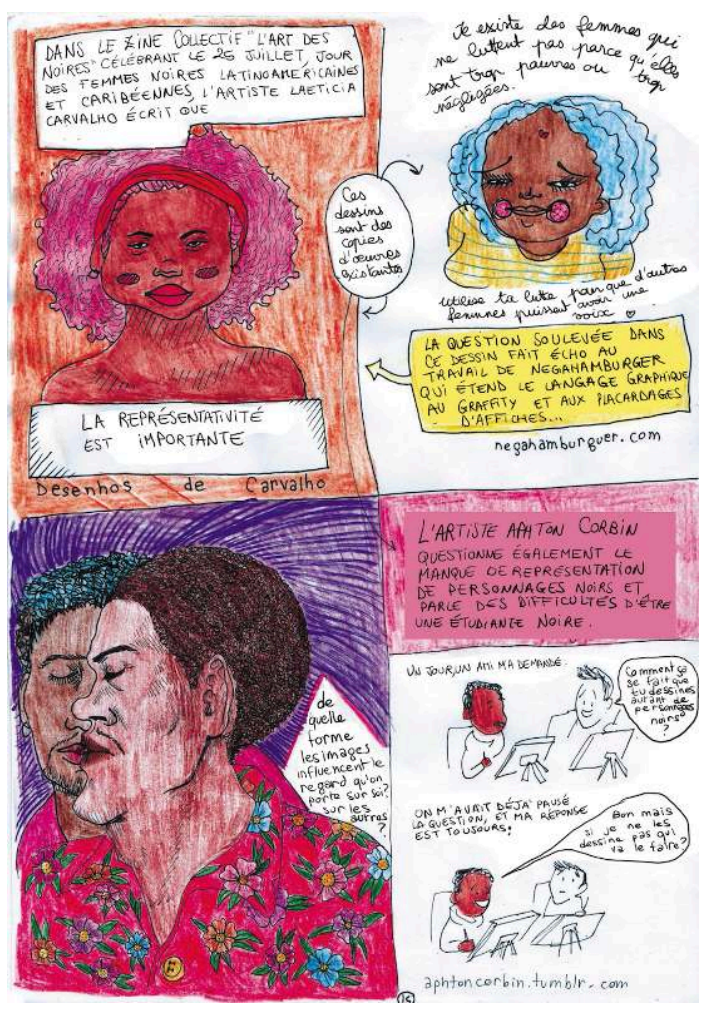

Se voir représentée et s'identifier

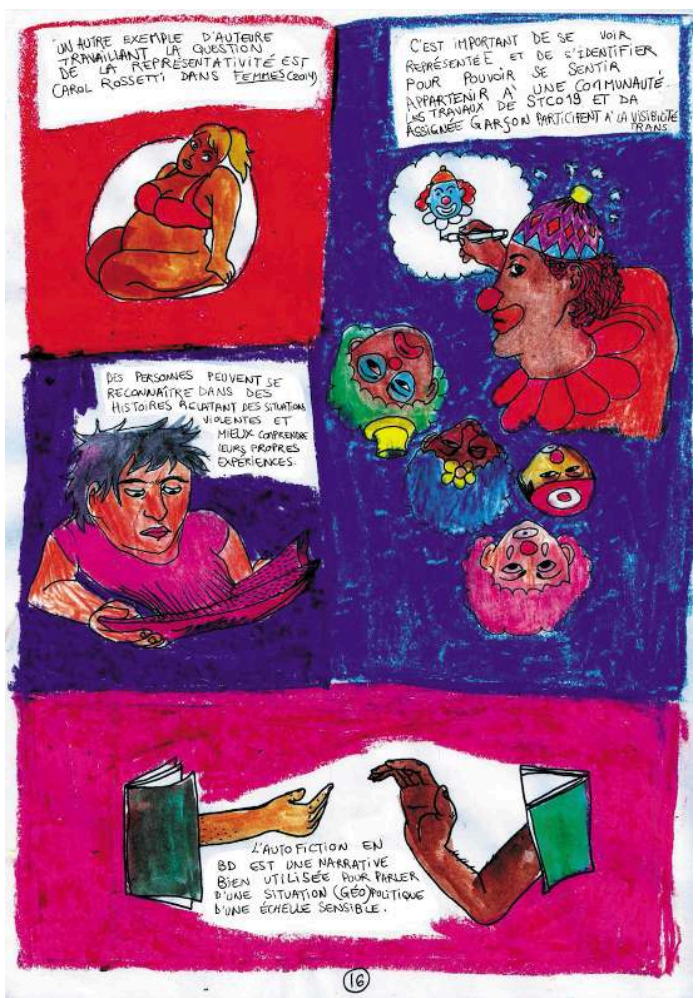


Représentation artistique et représentation politique

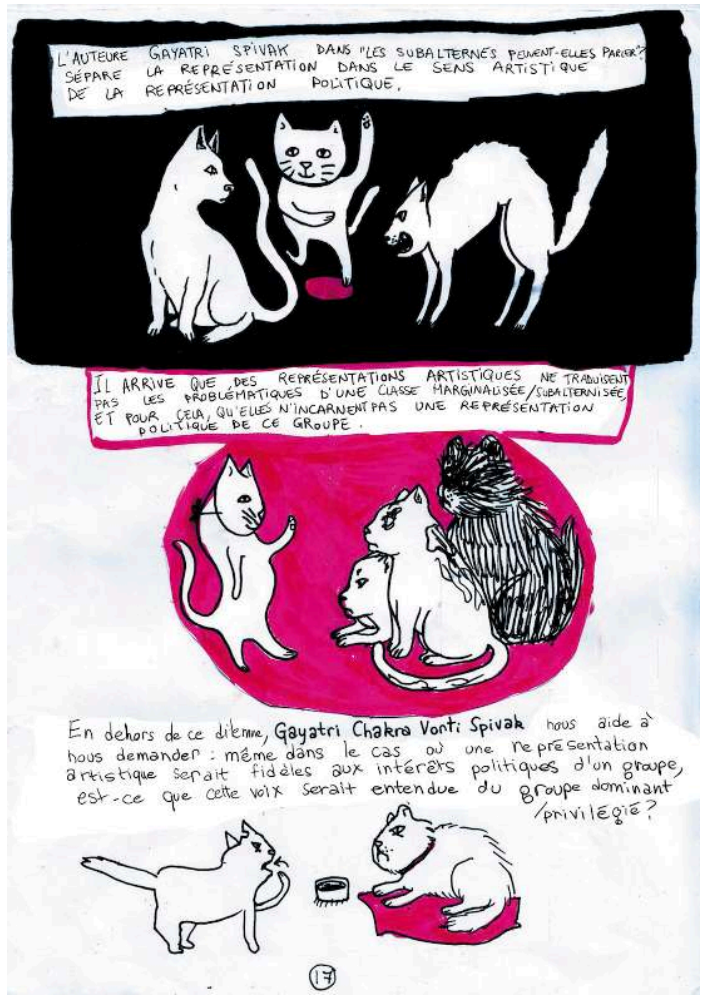

Construire de l'empathie

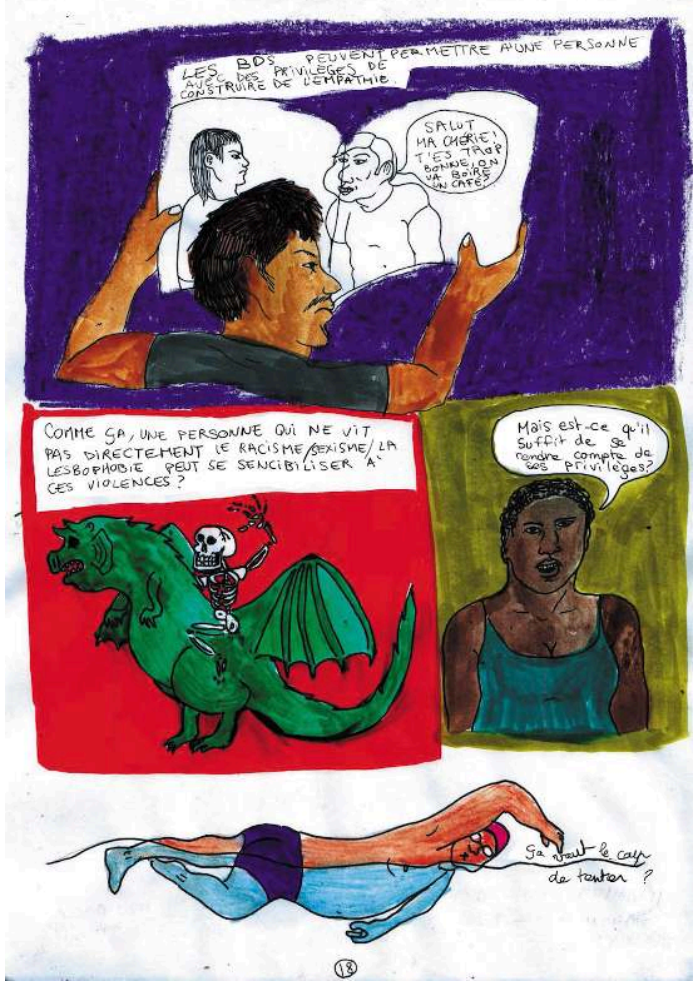


Surmonter les traumatismes

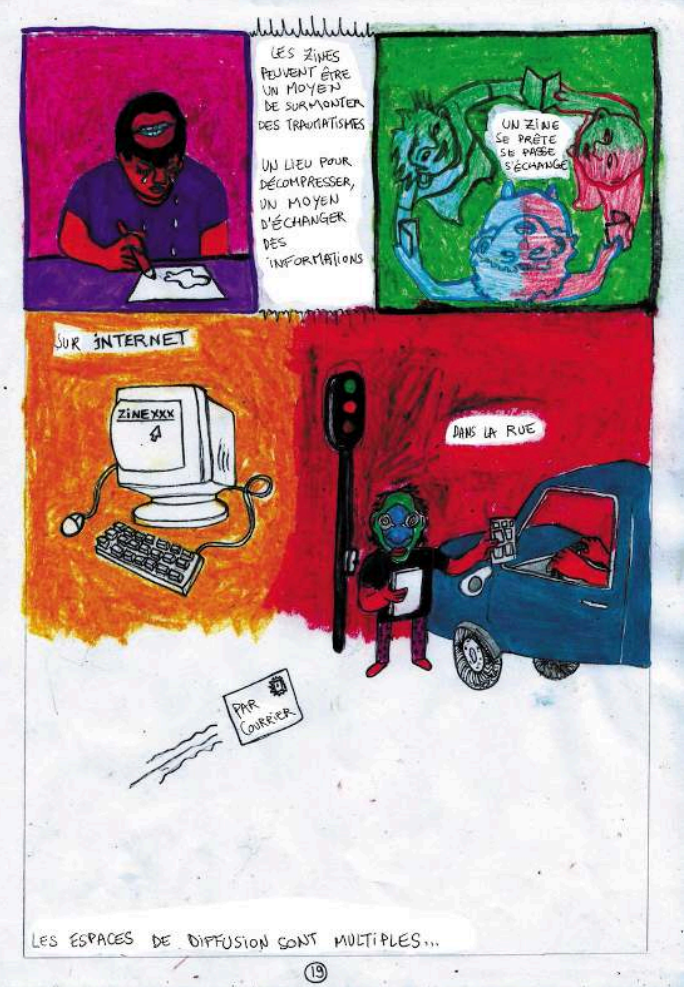

Qu'est-ce que les formes de communications non verbales amènent à la narrative ?

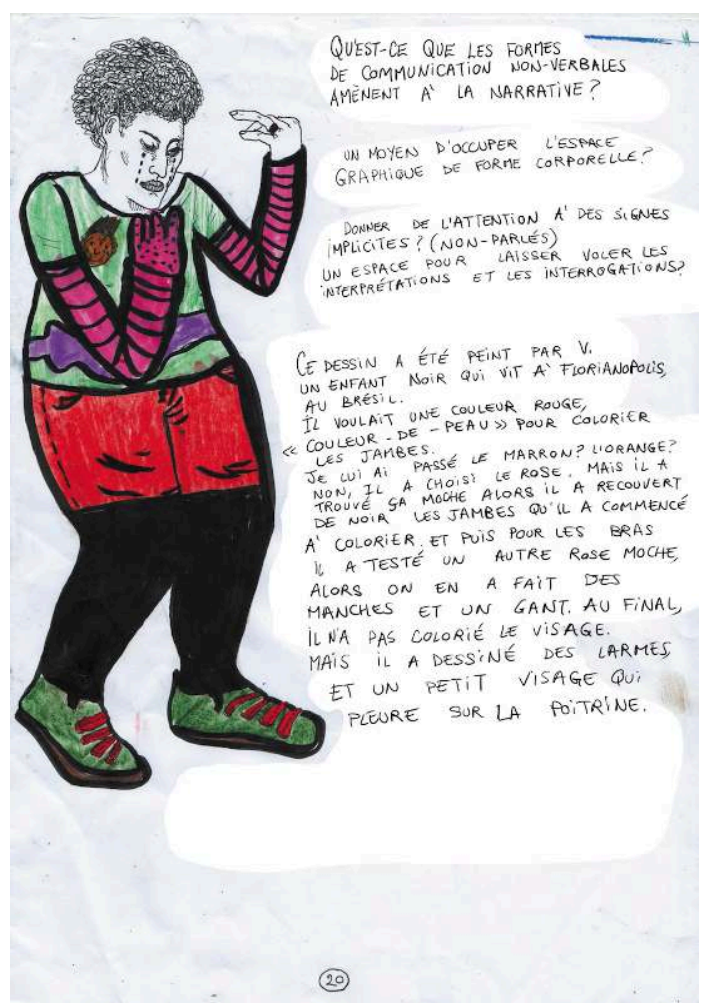



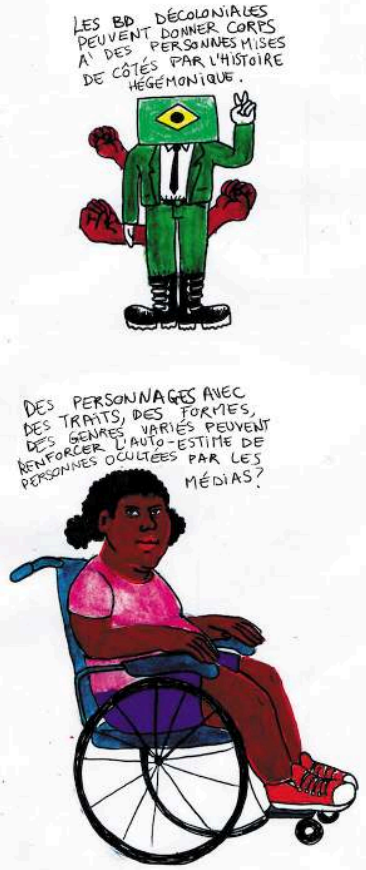

(21)

PAULO FREIRE?

Imaginer des ateliers de création libre
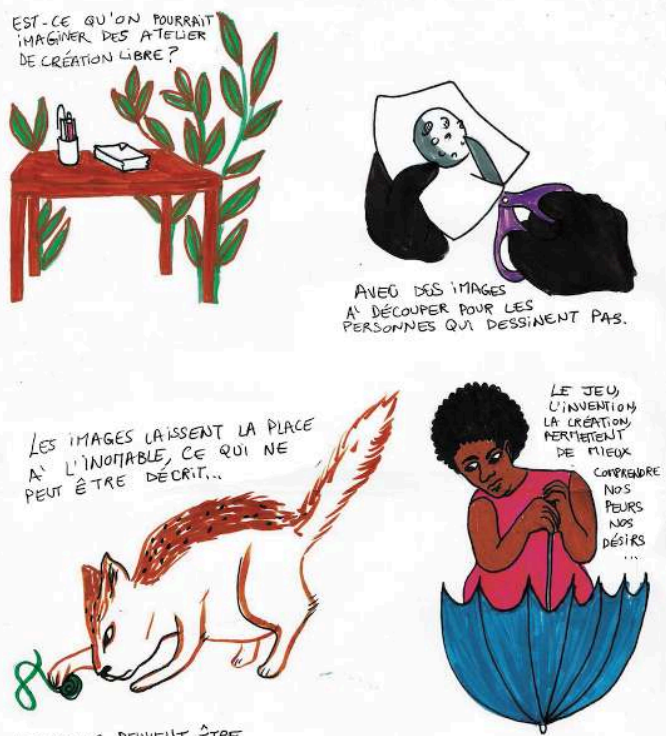

LES ZINES PEUVENT ETRE
WHE FORIE DE REAPROPRIATION

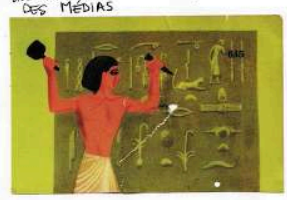

SUBSTITUANT LA- PUACE D'OBTET

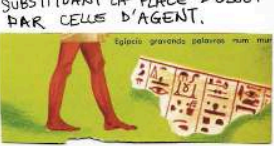

(22) 
Rendre visibles les différentes formes coloniales?

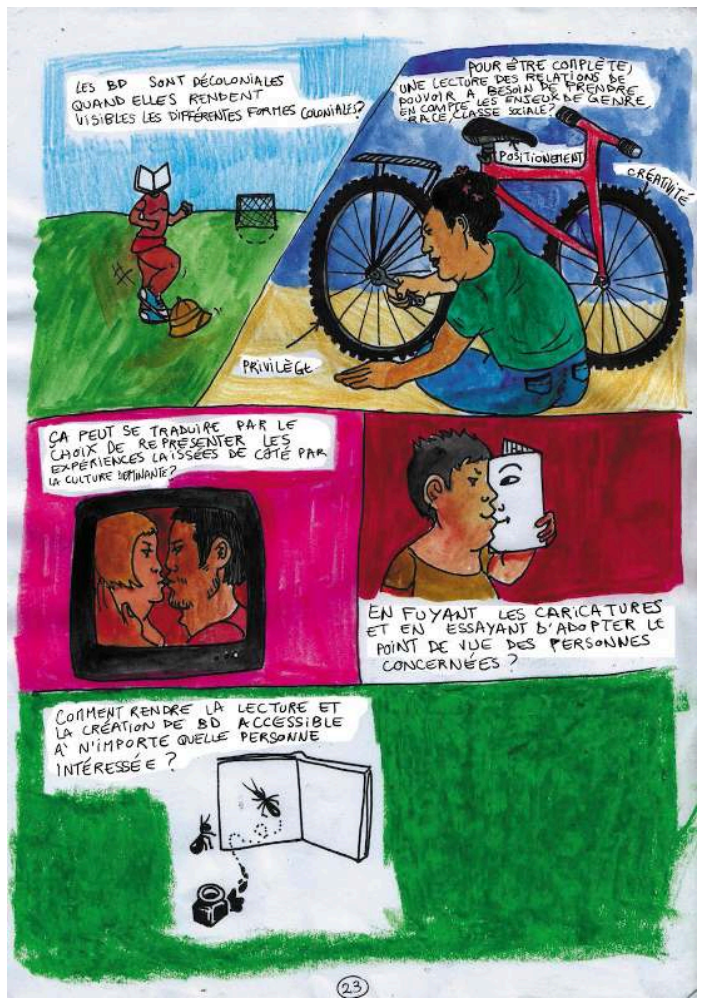

Est-ce que la production/lecture de BD se limite à la classe moyenne?

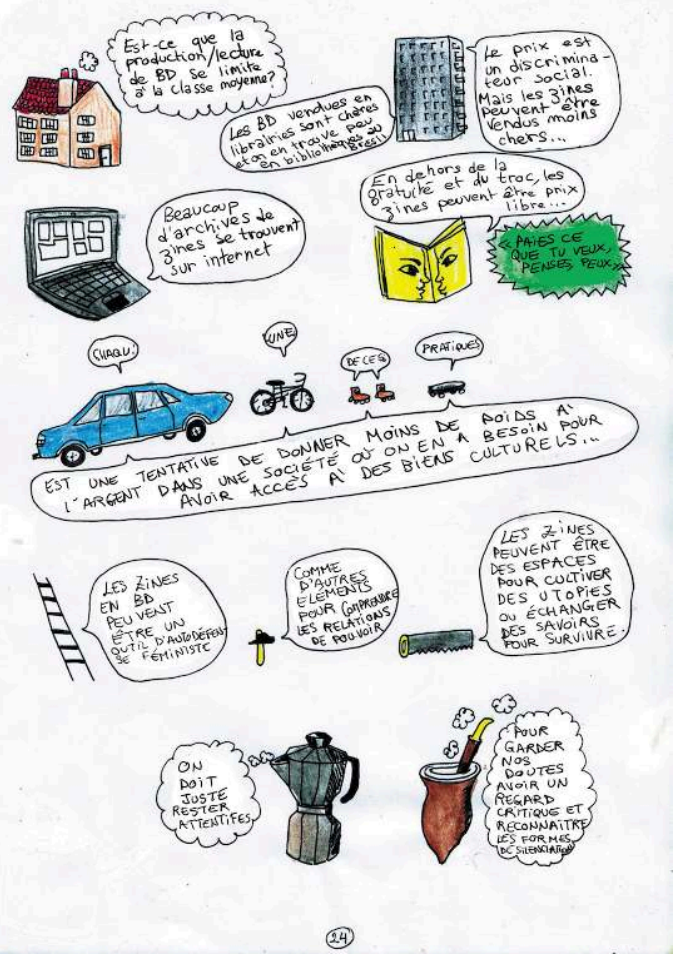




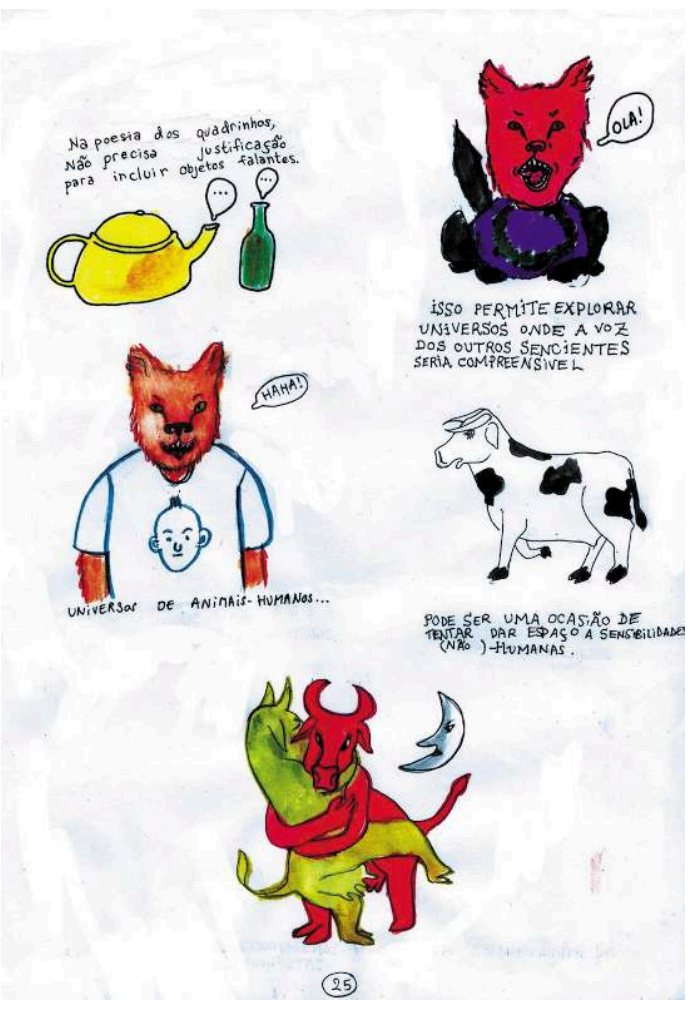

\section{RÉSUMÉS}

C'est une tentative d'explorer la BD comme un territoire politique. J'ai essayé de questionner le machisme et le racisme qui sont encore fortement présents dans la $\mathrm{BD}$, ainsi que les questions d'inégalités sociales qu'elle soulève. C'est une petite contribution à la critique décoloniale qui vise à reconnaitre l'eurocentrisme dans notre quotidien et notamment dans la production de savoirs. Et une invitation à utiliser la BD comme instrument de contre-culture ou contreinformation, pour pouvoir parler de nos expériences marginales à la première personne. Qui est représentéE ? Qui lit? Qui produit du savoir et de l'art?

É uma tentativa de explorar os quadrinhos como um território político. Tentei questionar o machismo e o racismo que estão presentes nos quadrinhos, assim como as questões de desigualdade sociais que eles levantam. É uma pequena contribuição para a crítica descolonial que tenta reconhecer o eurocentrismo no nosso quotidiano e na produção de conhecimentos. E é um convite a usar os quadrinhos como instrumento de contra-cultura o contra-informação, para poder falar de nossas experiencias marginais nas primeira pessoas. Quem é representade? Quem le? Quem produz sabedoria e arte? 
INDEX

Thèmes : Explorations

Palavras-chave : quadrinhos, descolonial, racismo, feminismo, zines

Mots-clés : BD, décolonial, racisme, féminisme, fanzines

\section{AUTEUR}

SUJAREI TALI

Colectivo Entulho https://entulhoviralatas.tumblr.com/

Ju, 23 ans, dessine en autodidacte, cuisine, coud, chante, fait du dessin animé... Dans le désordre et contre l'ordre établi. 